\title{
Apuntes para el urbanismo musulmán de Jaén: el alminar en la intervención de Martínez Molina-Los caños
}

$M^{a}$ del Carmen Pérez Martínez.

Yolanda Jiménez Morillas.

Juana Cano Carrillo.

El presente trabajo, Apuntes para el urbanismo musulmán de Jaén: el ALMINAR en la Intervención de Martínez Molina - Los Caños, pretende sumarse a los distintos estudios dedicados a la ciudad de Jaén, tras los resultados obtenidos de las intervenciones arqueológicas de urgencia en el casco histórico de la ciudad, que cada vez más nos refuerza la importancia de nuestro Patrimonio Histórico'.

El solar, se encuentra situado en pleno casco histórico, cercano a los baños árabes del Naranjo (C/ Los Caños), la vivienda musulmana (en las criptas de S. Juan), a los baños árabes del Palacio de Villardompardo etc... lo que, a priori, le convertía en uno de los ejes fundamentales para comprender tanto la dinámica urbana de la ciudad como la configuración de este área en concreto durante el período musulmán. Gracias a los datos recogidos antes de la intervención que vamos a analizar, la zona de Martínez Molina - Los Caños se configuraba como un espacio sin edificar hasta finales del S. Xl, fecha en la que se documenta la construcción del Baño del Naranjo, un espacio dedicado a vivienda y zonas abiertas ocupadas por descampados o probablemente por huertas. A raíz de todo ello se apuntaba que la actual trama urbana en esta área, y sobre todo, en la actual C/ Martínez Molina, es el resultado de las transformaciones urbanísticas durante los S. XIV - XV (CASTILLO ET ALII; JIMÉNEZ ET ALII,).

La importancia de esta excavación se basa fundamentalmente en que viene a reafirmar lo anteriormente expuesto permitiendo profundizar más en la configuración urbana de este área.

\section{LA INTERVENCIÓN DE MARTÍNEZ MOLINA - LOS CAÑOS}

El solar se encuentra en el extremo sureste de la ciudad respecto al cerro Sta. Catalina, en la zona más alta de la pendiente de la C/ Los Caños que parte de Martínez Molina (Fig. I). Su ubicación en pleno casco histórico y la construcción de un bloque de viviendas con aparcamientos hizo necesaria la intervención de urgencia ${ }^{2}$.

Durante la excavación se documentaron una serie de estructuras, asociadas a un conjunto cerámico, que puede ser fechado en torno a finales del s. XI y principios del XII (Fig. 2). Una conducción de agua excavada en la roca, de la que sólo se conservaba su base de lajas de piedra de tamaño mediano encajadas con otras más pequeñas. Un muro de mampostería

\footnotetext{
I Estas intervenciones por vía de urgencia se vienen realizando desde 1986 en todo nuestro casco histórico.

2 Los objetivos a lo largo de la excavación se formularon a raíz de los resultados obtenidos en las diversas intervenciones. Se procedió al planteamiento de tres cortes estratigráficos documentándose tres fases de ocupación: una primera islámica, la segunda fase cristiana, y la última, moderna-contemporánea (s. XVI-XX). Nos remitimos, no obstante, al informe donde se puede encontrar más información, en cuanto a la metodología arqueológica PÉREZ, JIMÉNEZ, CANO (1993) Intervención de Urgencia en la Cl Martínez Molina-Los Caños, en prensa.
} 
bastante irregular, sobre el nivel geológico, con dirección N - S, al que asociamos una zona de corral (por la abundancia de restos orgánicos en el interior de una fosa excavada en la roca). $Y$, un muro al que en su cara Sur se adosa el alminar, constituyendo su cierre norte que se extendía paralelo a la actual calle de Los Caños con dirección $\mathrm{E}-\mathrm{W}$, rompiendo el espacio de corral ya descrito. Este muro, debido al desnivel de la base geológica y a su perfecta adaptación a ésta, presenta varias fases de construcción: en contacto con la base es de piedras irregulares de tamaño mediano y en sus hiladas superiores se observa la alternancia de ladrillos con un sillar más regular; siendo además, el cierre norte del alminar (Fig. 2).

Por último, a nivel de superficie de la Calle Caños, encontramos el alminar (Fig. 2) (Lám. I), que sufrió continuas alteraciones constructivas desde época cristiana hasta nuestros días. No sabemos el momento en que este quedase reducido a este nivel, si bien durante la intervención se ha documentado una reutilización de la estructura para fines no religiosos desde el período medieval cristiano, momento en que se fabrica un pavimento empedrado a una cota bastante profunda respecto al nivel que se ubicaría la pavimentación originaria del alminar, utilizando claramente una de las canalizaciones musulmanas (Fig. 3). En este sentido pensamos que la mezquita pudo sufrir una dinámica similar al del Baño del Naranjo que tras la conquista cristiana fue repartido entre varios propietarios (SALVATIERRA ET ALII, 1993).

En época moderna-contemporánea, el alminar sufre una nueva alteración al construir un gran pilar de piedra en su interior, para después ser colmatado, consiguiendo así, una superficie estable que permitiese las construcción de una habitación perteneciente a la vivienda que se demolió antes de la intervención (Fig. 4).

Evidentemente, esta utilización continuada del espacio ha provocado la inexistencia de material musulmán estratificado así como de niveles estratigráficos verticales que aportasen una cronología relativa a la estructura. Por ello para su fechación nos hemos basado en los distintos paralelos constructivos de alminares recogidos por Torres Balbás y por Hernández Jiménez, y por su asociación con el material cerámico islámico recogido al exterior del alminar.

\section{EL ALMINAR}

\section{Descripción de su proceso constructivo.}

El alminar no aparece exento sino adosado al muro de dirección E-W (Fig. 2), como ya hemos mencionado. Es de planta cuadrada al exterior y cilíndrica en su interior como el alminar de S. Juan en Córdoba (HERNÁNDEZ, 1975).

Como comentábamos anteriormente, el alminar se encontraba prácticamente a nivel de superficie de la calle Caños, y a diferencia del alminar de Hisam I en la Mezquita Mayor de Córdoba, del que sólo se conservaban cuatro hiladas, en nuestro caso conservamos al interior unos 3 ó 3,20 m. y al exterior, según su alzado sur seis hiladas, que suponen $1,70 \mathrm{~m}$. La diferencia de potencia de los restos conservados se debe al proceso de construcción del alminar, en el que se realiza un continuo trabajo del nivel geológico y/o la adaptación de los muros al mismo; de este modo, aprovecharan la pendiente natural del terreno preparando la base geológica, tanto en su parte norte como oeste; de manera, que la estructura queda perfectamente encajonada en su nivel de cimiento, y su interior puede acoger el sistema de canalización.

El alminar fue fabricado a base de mampostería unida con argamasa (cal y arena); en algunas de sus uniones externas, perduran restos de cal (Fig 5 - 6). En el interior presenta sillares irregulares que oscilan entre 20 y $30 \mathrm{~cm}$. de longitud, con alternancia de lajas. El exterior, las dimensiones del sillar son mayores (60 a $75 \mathrm{~cm}$. de longitud), sin aparecer esta alternancia en el paramento (Fig. 7).

\footnotetext{
3 En las excavaciones arqueológicas se ha podido constatar que debido a las características físicas de la base geológica, caliza con afloramiento de margas y dolomías, permite ser excavada con cierta facilidad, favoreciendo de este modo la técnica constructiva del aterrazamiento artificial.
} 
El grosor de los muros externos es de 60 $\mathrm{cm}$. que aumentado con el adose de los semicírculos adquiere un grosor aproximado de I m., presentando un diámetro de $5.60 \times 4.60$ $m$., lo cual nos indica que no se trata de un cuadrado perfecto sino que presenta una tendencia rectangular.

Adosándose al muro de dirección E - W, y en un primer cuerpo de cimentación en contacto con la roca base, acoplan perfectamente dos muros situados al norte y al sur de dicho muro, que actúan como zunchos de cimentación para construir el perímetro cuadrangular externo, conformando un espacio rectangular inscrito en el cuadrado. Ambos muros, de sillería regular, tienen una funcionalidad de soporte constructivo, no obstante, el situado al sur, parece utilizarse también como "protección - separación" de una canalización (Fig. 3) que consta además de los atanores, de una canaleta de piedra caliza sobre un muro de hormigón.

Una vez realizado este primer cuerpo de cimentación, adosan, en el interior del cuadrado, los dos semicírculos que se observan en planta (Fig. 2). El situado al N, se asienta directamente sobre el muro correspondiente que le sirve de zapata, por el contrario, el situado al sur presenta varios puntos de apoyo; el muro sur, es utilizado sólo en sus dos extremos, el resto del semicírculo se apoya sobre el sistema de protección y cubrimiento de la canalización antes mencionada. Todo ello, crea un desnivel con respecto al anterior que se subsana con la construcción de una pequeña zapata en todo este tramo sur, para conectar con el muro norte y la zapata, donde pensamos se apoyaría el suelo principal.

Los espacios que quedan en las esquinas entre el cuadrado y el semicírculo, se rellenan con piedra y argamasa macizando por completo estos huecos. Se observa que las caras internas del cuadrado que iban a ser cegadas por el semicírculo no fueron cuidadas, mien- tras que las que quedaban vistas ( $E$ - W), presentan un aparejo de soga bien elaborado hasta su contacto con la base, hecho que nos manifiesta la existencia de un proyecto previo a la construcción, en el que ya se preveía la estructura circular interna y por tanto esta no es un añadido posteriori como a primera vista podría parecer.

\section{Las conducciones de agua.}

Es interesante señalar el sistema hidráulico que se inserta en el propio alminar, como también aparece en el alminar de Hisam I, en la Mezquita Mayor de Córdoba4. En su interior se constataron tres canalizaciones, imbricadas en su sistema constructivo, pertenecientes al período musulmán. Pudimos constatar la reutilización de una de ellas durante la etapa cristiana por su asociación al pavimento empedrado (Fig. 3).

El sistema situado a un nivel más alto, se ubica al sur de la estructura; protegida -como ya hemos señalado- tanto por el muro de cimiento sur como por dos muros de hormigón que la flaquean. La canalización se conforma en base a atanores de gran tamaño ( $43 x$ $18 \mathrm{~cm}$ ) con dirección W - SE, que se acoplan perfectamente a una canaleta de piedra caliza cubierta por una gran losa. El atanor desemboca en un sistema de tejas $(4 \mathrm{I} \times 16 \mathrm{~cm})$ vidriadas al interior y cubiertas igualmente por grandes losas.

La segunda canalización aparece en la base geológica, siendo un poco reexcavada para introducir los atanores cerámicos $(42 \times 20 \mathrm{~cm}$ y $42 \times 15 \mathrm{~cm}$ ), y dos muros de hormigón que la protegen, aunque el sistema de protección se acentúa al estar recubiertos estos atanores con tejas $(41 \times 16 \mathrm{~cm})$ y finalmente, sellado con una capa de hormigón.

Por último, la que está situada hacia el NE y desemboca hacia el SE. Probablemente, como resguardo y posible acceso a la misma realizan un murete de ladrillo conformando así, una pequeña arqueta. La canalización está

\footnotetext{
4 En el alminar de Hisam I de la Mezquita mayor de Córdoba "quedan en su parte interior restos de una galería con apariencia de conducción de agua" (HERNÁNDEZ, 1975).
} 
constituida con atanores cerámicos algo mayores a los anteriores $(45 \times 18 \mathrm{~cm}$. y $45 \times$ $10 \mathrm{~cm}$.), si bien no presenta un sistema de protección tan fuerte como los anteriores.

Ahora bien, realizando un paralelismo con respecto a otros alminares (recogidos por Hernández Jiménez y Torres Balbás), elementos tales como el vano de acceso, la existencia del machón central que soporta la escalera, o su conexión con la mezquita quedan como hipótesis, ya que, no podemos olvidar que el alminar, por un lado, apareció a nivel de calle y por otro, ha sufrido importantes modificaciones y/o alteraciones al ser reutilizado en períodos posteriores. No sabemos la funcionalidad que se le asignó en época medieval cristiana, probablemente fuese bastante marginal. Posteriormente debió sufrir un proceso de abandono que derivaría en su demolición produciéndose su sellado y alteración constructiva para edificar un pilar en la vivienda que existía sobre él, y provocando que estos elementos no se conserven en el registro arqueológico.

En cuanto al acceso al mismo, la única posibilidad de entrada se encontraba al este donde existe una apertura de 1,04 m. Desgraciadamente no se conserva su cara externa en este lado debido al levantamiento del edificio existente y su respectiva fosa de cimentación que, evidentemente, rompe casi la totalidad de este espacio. No obstante, esta posibilidad parece reforzarse ya que, al analizar los restantes paramentos no se constató ninguna alteración de fábrica que indicase un cegamiento posterior, descartando así que pudieran existir más puertas (como es el caso de la mezquita Mayor de Córdoba). Estas dimensiones (I,04 m.) se aproximan al resto de los alminares conocidos "en el de la Giralda, y en la Torre de Hassam de Rabat, sin disputa los mayores de ellos, el acceso se produce por puerta en que dos personas no se cruzan con excesiva holgura" (HERNÁNDEZ, 1975).

Por otra parte, las dimensiones en planta de la estructura sugieren una altura considerable que hace imprescindible la presencia de una escalera. No obstante este elemento no ha sido localizado debido a las continuas reuti- lizaciones ya mencionadas. Según los alminares conocidos de planta cuadrada al exterior y circular al interior presenta un sistema de escalera de caracol con machón central interno (cuadrado, rectangular o cilíndrico) por lo que a nuestro juicio este minarete debió presentar un esquema similar, el sistema de peldañaje debía quedar de la siguiente manera: el muro sur de cimentación interna no debería de alcanzar una altura superior al constatado siendo probablemente similar al muro norte. El primer tramo de escalera partiría desde la puerta, girando a la izquierda y tomando como punto de apoyo el muro sur, giraría nuevamente a la derecha desarrollándose a partir de aquí el típico sistema de caracol.

Según Torres Balbás, este tipo de alminar es propio de la segunda mitad del S. X, no obstante, el inicio de construcción de este minarete es bastante más tardío, por su posible identificación en las fuentes musulmanas y por la asociación del material.

La identificación de esta mezquita en las fuentes musulmanas es bastante difícil. Las fuentes escritas citan tres mezquitas en Jaén, aunque probablemente hubiese más. A las dos sucesivas aljamas ya identificadas (AGUIRRE, 1982) se une la mencionada por el autor jiennense Ibn Zulayr (S. XIII), al hacer la biografía de un paisano suyo llamado Yusuf b. Tacayyasit, fallecido hacia 1222. El biógrafo subraya que éste dedicó toda su vida a la enseñanza del Corán en la mezquita de Ali 'Abd Allah al-Bagdadi de Jaén.

Javier Aguirre (1982) ha propuesto identificar al personaje que dio su nombre a esta mezquita con Ali ${ }^{C}$ Abd Allah Muhammad b. Ahmad al-Jazrayt -cuya biografía recoge Ibn alAllat-, natural de Jaén, donde nació en 1078, y que era conocido como al-Bagdadi por haber residido en aquella capital durante muchos años, y que, después de regresar a AlAndalus, marchó a Fez donde murió en II52.

Dicha mezquita pudo ser construida en honor del Alfaquí, y en este caso habría que fecharla en la época de su muerte o pocos años después. Pero si tenemos en cuenta 
que el personaje marchó y murió en Fez, es posible que se diese popularmente su nombre a la mezquita en la que enseñaba durante su estancia en Jaén, tras haber vuelto de Bagdad, nombre que luego perduraría. En este caso la mezquita habría sido construida con anterioridad. Tampoco pudo ser muy antigua, ya que entonces habría arraigado su nombre original, y habría sido más difícil la fijación del de Al-Bagdadi.

Tenemos por tanto la reseña de una mezquita aún no identificada, que pudo ser construida entre mediados del S. XI y el tercer tercio del siglo XII, y unos restos que pueden identificarse con un alminar que en base al material recogido presenta una cronología similar.

Por otra parte, y estrechamente relacionado al alminar, no es extraña la existencia de su importante sistema hidráulico, ya que, existen abundantes referencias en fuentes escritas desde el período musulmán, de la riqueza acuífera de la ciudad de Jaén, que contaba con un buen número de manantiales entre los que destaca el de la fuente de la Magdalena por su abundancia de agua. El profesor Vicente Salvatierra (SALVATIERRA ET ALII, 1993) apuntó que el ramal con dirección E-SE, que partía de la fuente de la Magdalena, fue canalizado hasta alcanzar la actual plaza Los Caños para surtir de agua las calderas del Baño del Naranjo, vertiendo el sobrante por Arroyo S. Pedro. Si tenemos en cuenta las entubaciones documentadas parece probable que este ramal fuese encauzado en dos vías (PÉREZ, ALCÁZAR, 1993) corriendo la segunda en una cota superior, probablemente próxima a la calle Martínez Molina.

De este modo, nos encontramos que en el alminar hay proyectado, un perfecto acoplamiento de las canalizaciones y con una fuerte protección de éstas, que nos sugieren que fueron concebidas para portar agua limpia; si a ello unimos una serie de cuestiones como: a) Todas convergen hacia el SE -en dirección al Baño-.

b) El alminar no es exento, lo que implica que el acceso al mismo habrá de realizarse desde el patio.

c) La puerta se ubica al E.

Podemos establecer, que el patio de la posible mezquita, siguiendo los esquemas de los distintos accesos desde el patio, debía estar, al menos, lindando con el baño, y que estas canalizaciones surtían de agua a la fuente de abluciones y probablemente a las piletas del Baño ${ }^{5}$.

A raíz de todo lo expuesto podríamos establecer, si bien con ciertas reservas ${ }^{6}$, el emplazamiento de esta mezquita.

- El límite este correría paralelo al Baño del Naranjo.

- El límite oeste, en base a la dirección del muro de cierre, la terraza constatada en la calle Martínez Molina y la fuerte pendiente en la que se asienta la Iglesia de S. Juan, no debió alcanzar una cota superior a la calle, si bien ésta pudo ser ocupada en su totalidad.

- El norte vendría delimitado por el muro E $W$ al que se adosa el alminar.

- El sur nos es desconocido y casi sin posibilidades de conocerlo por la existencia de edificaciones de nueva factura.

\section{APUNTES PARA EL URBANISMO MUSULMÁN}

Gracias a todos estos datos y a las restantes intervenciones, podemos realizar un diseño aproximado de la evolución urbana del área en que se ubica el solar.

\footnotetext{
5 Por ello, es difícil señalar su acceso desde el Oratorio como ocurre en la Giralda.

6 Está abierta a cualquier modificación con futuras excavaciones o recogida de más fuentes literarias que nos ayuden en nuestro trabajo.
} 
Contamos con tres edificaciones, alminar, baño, y vivienda que presentan una cronología no anterior al S. XI. Tampoco se han encontrado niveles de ocupación anteriores, lo que nos sugiere que este área será un punto de partida para la expansión urbana de la ciudad hacia el SE.

Durante el período emiral y califal, este espacio no edificado, estuvo ocupado por huertos como parece atestiguarlo la acequia de riego inutilizada por los cimientos del Baño y el espacio de corral que se ha documentado en la excavación analizada y en sus proximidades se situaba otro huerto de posible origen islámico: el Corral de Hernán Ruiz de Ballarta, que citan las fuentes de principios del S. XVI (SALVATIERRA, CASTILLO, CASTILLO, 1993). Las fuentes son ambiguas respecto a su ubicación, no obstante, parece probable que se ubicara frente al Baño, en la actual manzana de casas delimitadas, en su parte superior por la calle Martínez Molina, y por abajo con la fuente los Caños. De este modo, el solar excavado en el $n^{\circ} 72$ de la Calle Martínez Molina (SERRANO, MARTINEZ, en prensa) podría haber formado parte de dicho corral, ya que se documentó que dicho solar se mantuvo sin edificar hasta el S. XVII-XVIII.

Junto a los huertos, la fuerte pendiente del terreno, y el perfil abrupto del mismo, sugieren la existencia de descampados. Esta hipótesis parece ratificarse con la intervención en la Iglesia de S. Juan; los sondeos realizados en la zona de culto, demostraron que la primitiva Iglesia gótica (S. XIII), fue una construcción de nueva planta en una gran pendiente nunca edificada en momentos anteriores. Del mismo modo, en el $n^{\circ} 3$ de la calle $S$. Juan, se documentó una secuencia estratigráfica cuyo nivel más antiguo pertenecía a los S. XIV - XV.

La existencia de un gran espacio sin edificar hasta el S. Xl, podría corroborarse con la misma planta del Baño que presenta un disposición en doble codo (Mahsla, Bayt al-Barid y Bayt al-Wastany), lo que supone una muy generosa distribución del espacio, impensable si la construcción del baño hubiese estado condicionada por un entorno edificado.
La aparente contemporaneidad de estas intervenciones urbanísticas -construcción de dos edificios de uso público, habilitación de un sofisticado entramado hidráulico para su abastecimiento perfectamente imbricado en ambas estructuras-, no parece ser un hecho fortuito. Por el contrario, parece responder a una cierta voluntad del poder político de organización urbana, en una zona deshabitada y de gran extensión, elegida además porque permitía el fácil encauzamiento de los arroyos cercanos a ella. Estas características la hacían óptima para ejecutar en ella la construcción de un espacio público, formado por el binomio baño-mezquita, en la más clásica tradición islámica. Por el momento se trata sólo de una hipótesis, no obstante, sería interesante una revisión, a raíz de los nuevos datos aportados por la investigación arqueológica, de los presupuestos que describen el urbanismo musulmán como desorganizado, anárquico y fruto del crecimiento "natural".

La construcción de ambos edificios sería la respuesta a las necesidades de una ciudad con una progresión urbana constante, reflejo del crecimiento poblacional y del esplendor económico y cultural de este período. Esta ampliación quedó verificada en la vivienda aparecida en las Criptas de la Iglesia de S. Juan, pues la dirección de sus muros hace pensar que sus habitaciones ocuparían gran parte de la actual calle Martínez Molina al igual que el muro de cierre de la posible mezquita y al que se adosa el alminar, como mencionamos anteriormente. Es más, si observamos la figura $n^{\circ} 8$, el nivel de calle actual está a 3 metros por encima de la base geológica, y sobre todos los restos de época musulmana constatada en la zona, por lo que, la teoría que han mantenido diversos autores (LAZARO, 1988; DE ULIERTE, 1990), de que esta calle constituía una de las vías maestras que articulaba la ciudad uniendo sus extremos occidental y oriental, quedaría en entredicho (CASTILLO Y CASTILLO, 1991).

Teniendo en cuenta este hecho, debemos acabar con el mito de que el actual casco histórico de la ciudad de Jaén es fundamentalmente musulmán, ya que, como se viene demostrando con los trabajos arqueológicos, 
nuestra ciudad es fruto de las profundas modificaciones realizadas desde el período medieval cristiano hasta nuestro días, estando construida sobre la colmatación de la urbe ibero-romana y musulmana.

Por último sería interesante reseñar la utilización del sistema de aterrazamiento para la construcción de los edificios menciona-dos?. Se han podido constatar dos técnicas de aterrazamiento: allanando la superficie de las terrazas naturales, o fabricando una terraza artificial (favorecido por el nivel geológico). Esta última técnica es la utilizada para la construcción del Baño, donde observamos cómo el nivel de la base geológica ha sido rebajada y nivelada para situar encima de ella el pavimento; en el alminar, donde los niveles naturales de la roca han sido cortados para asentar sólidamente los cimientos del mismo y en la casa islámica documentada en las criptas de S. Juan.

En definitiva, el área actual de S. Juan - Los Caños, donde se asienta el Alminar analizado, fue en su momento el foco de expansión urbana que sufrió la ciudad de Jaén en el $\mathrm{S}$. $\mathrm{XI}$. Será ahora cuando las áreas residenciales desbordará los antiguos límites de la urbe iberorromana donde se centró la ciudad emiral y califal, para expandirse por espacios hasta entonces despoblados. No obstante, no debemos imaginarnos un hábitat abigarrado, sombrío y sin espacios abiertos, sino que estos últimos continuaron existiendo, como se ha demostrado tanto arqueológicamente en la zona de culto y en las proximidades de la Iglesia de S. Juan, como en las fuentes escritas, con el llamado corral de Hernán Ruyz de Ballarta. Igualmente, para comprender el urbanismo musulmán, debemos tener en cuenta que los espacios dedicados a jardines, huertas o patios son elementos fundamentales de la casa islámica, por lo que en Jaén debieron también existir espacios abiertos, pero confinados en un ámbito privado.

\section{BIBLIOGRAFÍA}

AGUIRRE SÁDABA, F.J.: "El Jaén Islámico", en Historia de Jaén, Diputación Provincial. Colegio Universitario, Jaén, 1982, pp. 159 - 200

AGUIRRE SÁDABA, F.j:; SALVATIERRA CUENCA, V.: "Cuando Jaén era Yayyan", en Jaén. Vol. II, Historia. Granada, 1989, pp. 453 - 490.

CASTILLO ARMENTEROS, I.C.; CASTILLO ARMENTEROS, J.L.: "Nuevos datos sobre el urbanismo del Jaén Islámico: las Criptas de la Iglesia de S. Juan (Jaén)", en Miscelánea de Estudios Arabes y Hebraicos, n 19, Granada, 1991.

DE ULIERTE, L:: Jaén. La ciudad y su historia. Granada, 1990.

ESTEBAN MARFIL, A.: "Excavación de urgencia en el solar n 3 de la calle S. Juan", Anuario Arqueológico de Andalucía, en prensa.

HERNÁNDEZ JIMÉNEZ, F.: El Alminar de 'Abd al Rahman III en la Mezquita Mayor de Córdoba. Génesis y repercusiones. Patronato de la Alhambra, Granada, 1975.

LÁZARO, Ma S.: Desarrollo histórico del casco urbano de Jaén hasta 1600. Jaén, 1978.

PÉREZ MARTÍNEZ, Ma. C.; ALCÁZAR HER-NÁNDEZ, E.: "Nuevas aportaciones al urbanismo de Jaén" en El Baño Árabe del Naranjo y la formación del edificio los Caños. Jaén, 1993.

PÉREZ MARTÍNEZ, Ma C.; JIMÉNEZ MORILLAS, Y.; CANO CARRILLO, .:. "Intervención arqueológica en el solar situado en Martínez Molina y Los Caños", Anuario Arqueológico de Andalucía, 1992, en prensa.

SALVATIERRA et alii.: El Baño Árabe del Naranjo y la formación del edificio los Caños. Jaén, 1993.

SERRANO PEÑA, J.L.; PÉREZ MARTÍNEZ, M.C.: "Excavación arqueológica de urgencia en la calle Martínez Molina n 72", Anuario Arqueológico de Andalucía, 1991, en prensa.

TORRES BALBAS, L.: "Alminares Hispano musulmanes", en Cuadernos de Arte. Facultad de Letras de Granada, IV - VI, 1939 - 194I, pp. 59 - 90.

TORRES BALBAS, L.: "La Mezquita Mayor de Qayrawân", en Obra Dispersa I. Al - Andalus. Crónica de la España Musulmana I. Madrid, I98I, pp. 53 - 57.

TORRES BALBAS, L:: "La Mezquita de al-Qarawiyîn de Fez y el aprovechamiento de elementos arquitectónicos califales", en Obra Dispersa I. Al - Andalus. Crónica de la España Musulmana I. Madrid, 1981, pp. 59 - 6I.

7 Véase la nota a pie $n^{\circ} 3$

8 En la misma línea, en los diversos sondeos arqueológicos realizados tanto en la zona de culto como el las criptas de la iglesia de S. Juan, se evidenció la fuerte pendiente natural del terreno, que hace que, la primera se sitúe aproximadamente a unos $4 \mathrm{~m}$. por encima de las segundas. Pero el hecho que más llamó la atención fue el gran desnivel de unos 2,5 m., existente entre los dos sondeos realizados en las criptas. En este espacio tan reducido, tal diferencia sólo puede estar motivada por la excavación de una terraza artificial para la construcción de la casa islámica (Castillo, Castillo, en prensa). 
TORRES BALBAS, L.: "Dos obras de arquitectura almohade: la Mezquita de Cuatrohabitan y el Castillo de Alcalá de Guadaira", en Obra Dispersa I. Al - Andalus. Crónica de la España Musulmana I. Madrid, 1981, pp. $276-288$.

TORRES BALBAS, L.: "El alminar de la Iglesia de S. José y las construcciones de los ziries granadinos", en Obra Dispersa I. Al - Andalus. Crónica de la España Musulmana 2. Madrid, 1982, pp. 22 - 44.

TORRES BALBAS, L.: "La Mezquita de al-Qanatir y el santuario de Alfonso el Sabio en el Puerto de Sta. María", en Obra Dispersa I. Al - Andalus. Crónica de la España Musulmana 2. Madrid, 1982, pp. 149 - 172.
TORRES BALBAS, L.: "La Mezquita de la Alcazaba de Badajoz", en Obra Dispersa I. Al - Andalus. Crónica de la España Musulmana 2. Madrid, 1982, pp. 256 -260.

TORRES BALBAS, L.: "Los alminares de las mezquitas hispanas", en Obra Dispersa I. Al - Andalus. Crónica de la España Musulmana 3. Madrid, 1982, pp. 6I - 7I.

TORRES BALBAS, L.: "La primitiva Mezquita Mayor de Sevilla", en Obra Dispersa I. Al - Andalus. Crónica de la España Musulmana 3. Madrid, 1982, pp. 197 - 213. 


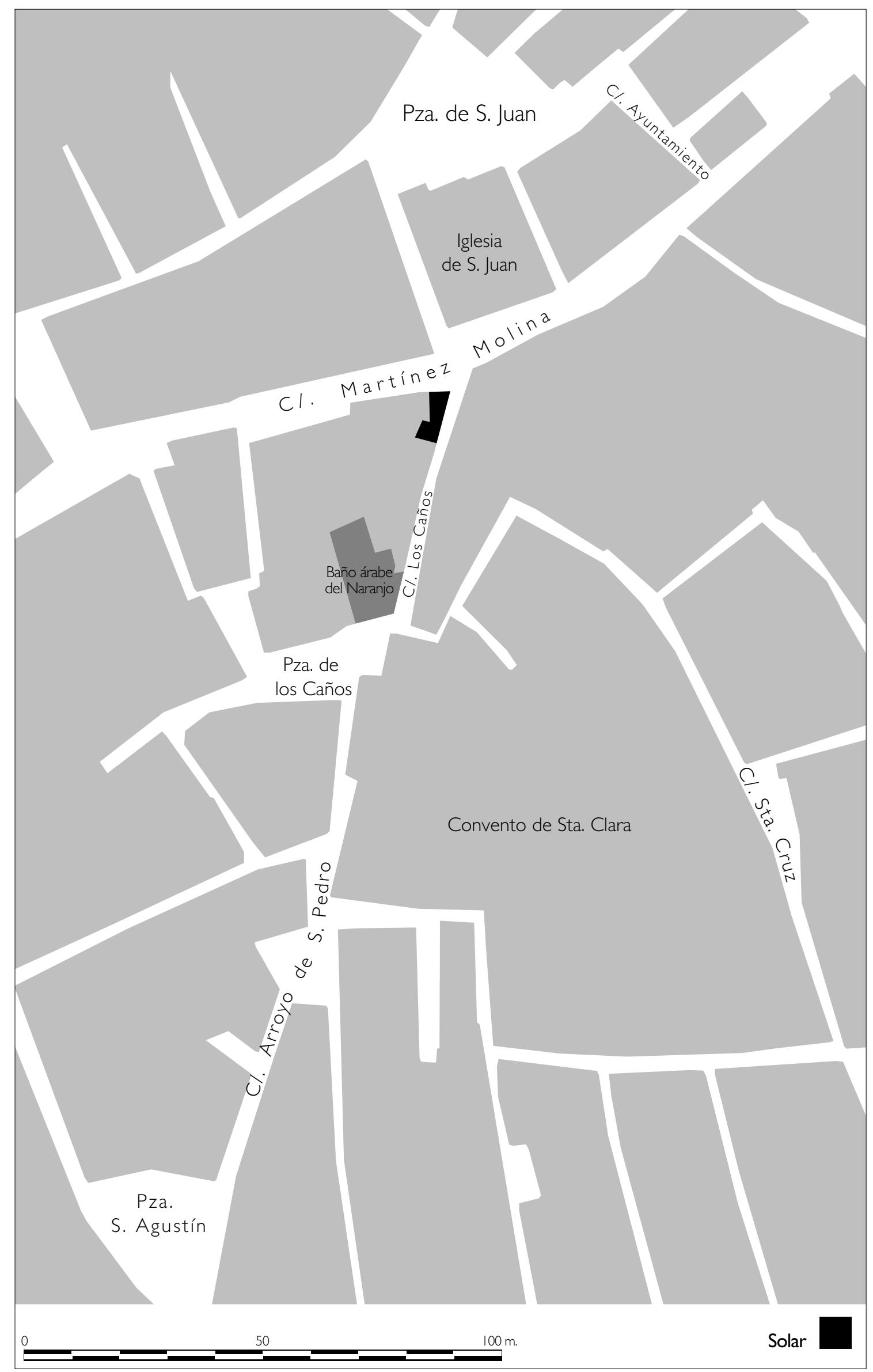

Fig. I 


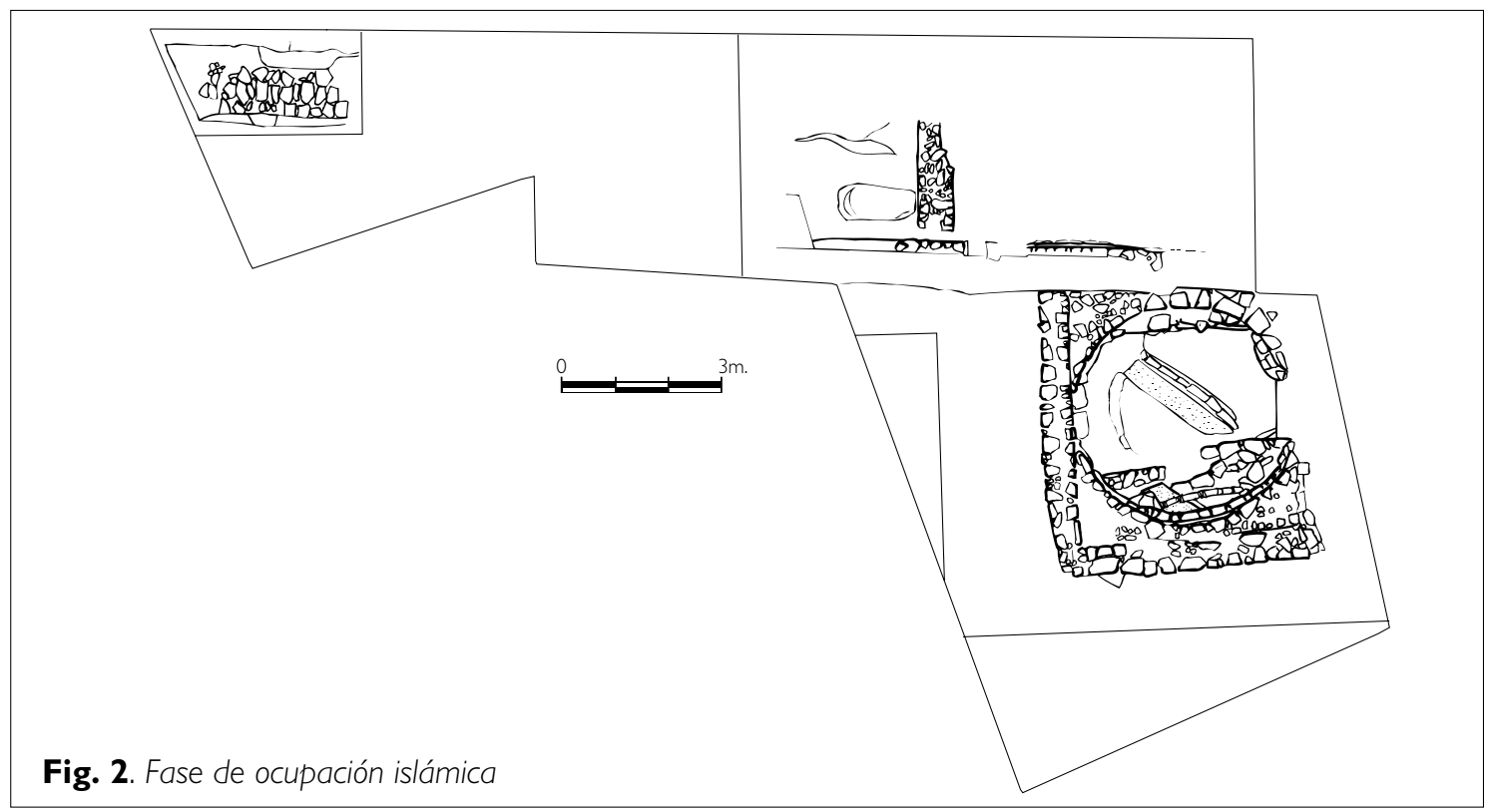

Fig. 3. Fase de ocupación cristiana
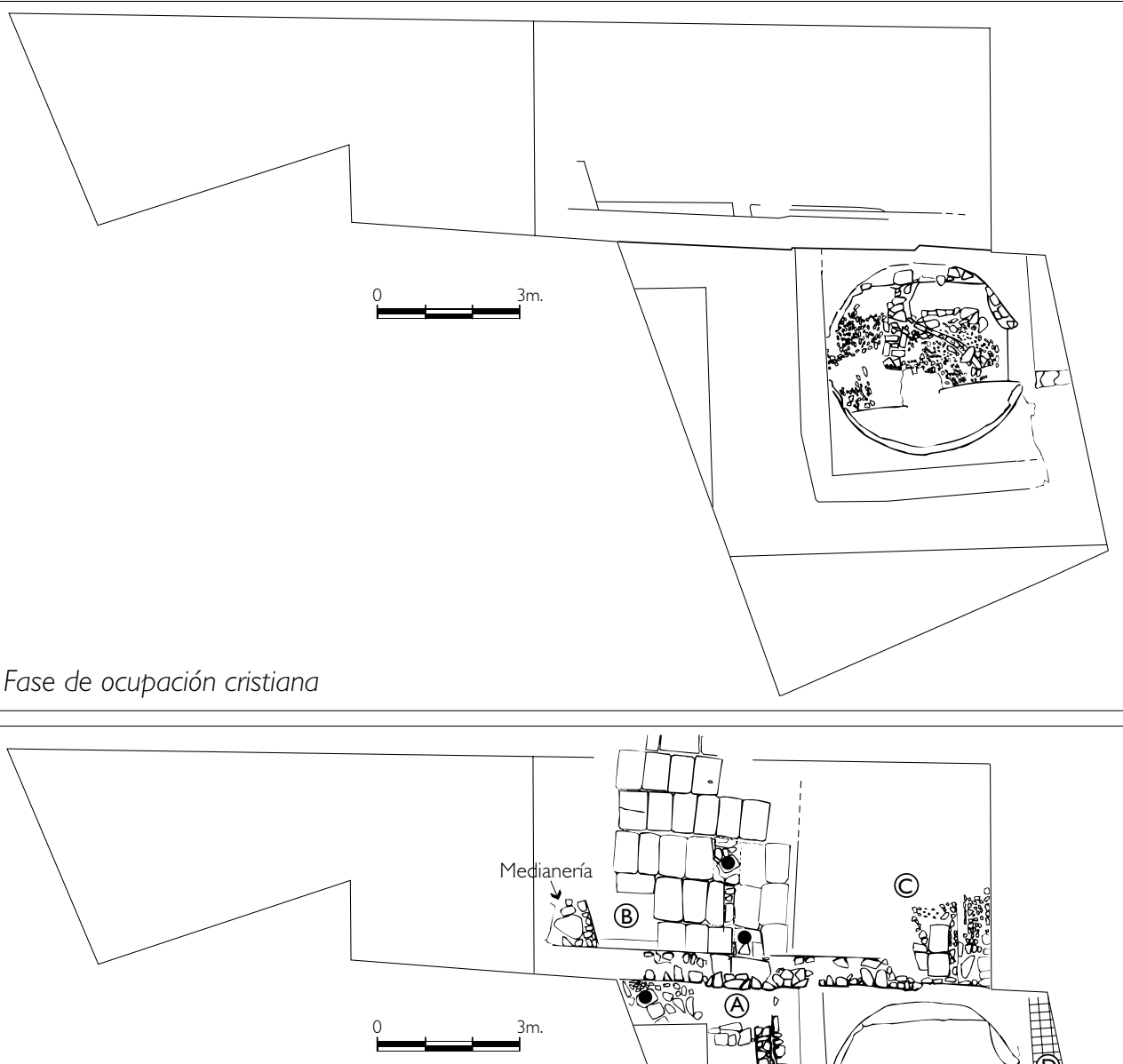

- Atarjeas

Fig. 4. Fase de ocupación moderna-contemporánea

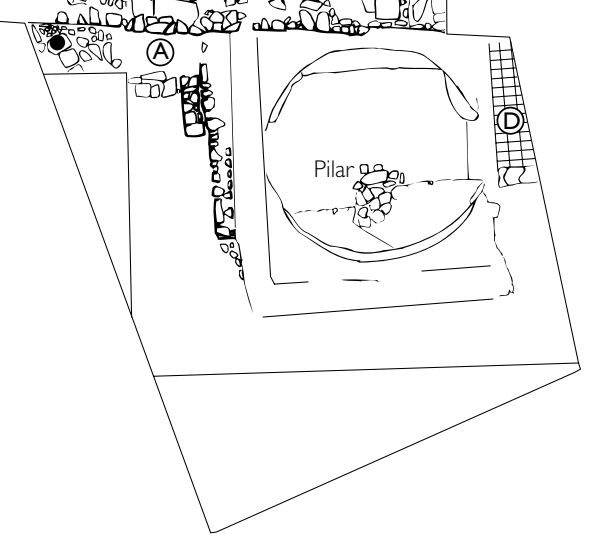


C/ 3

ALZADO SUR

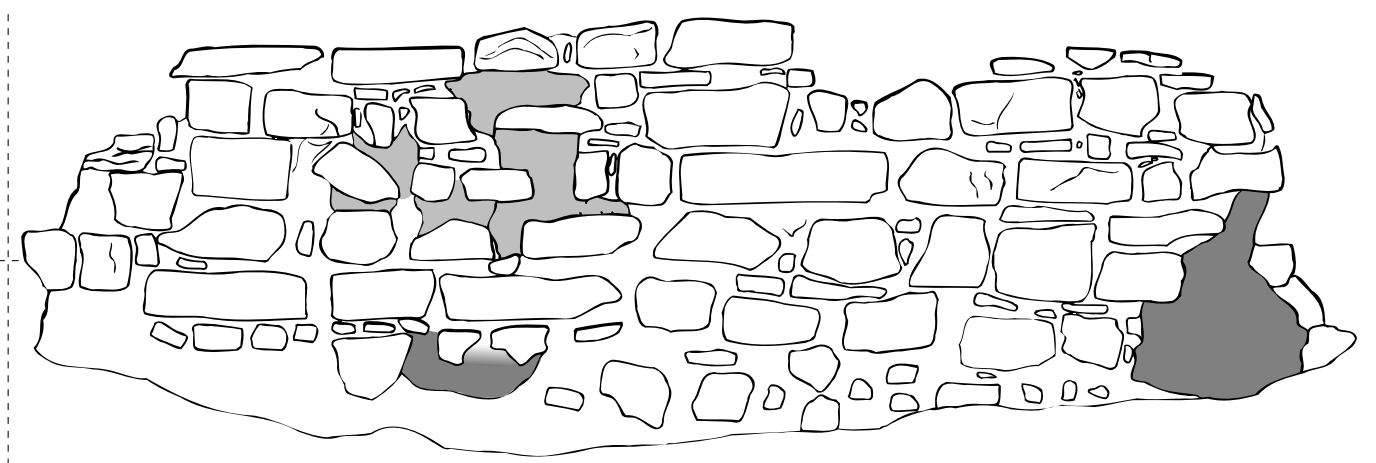

Yeso

Argamasa naranja

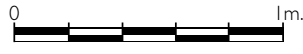

Fig. 5

C/ 3

ALZADO OESTE

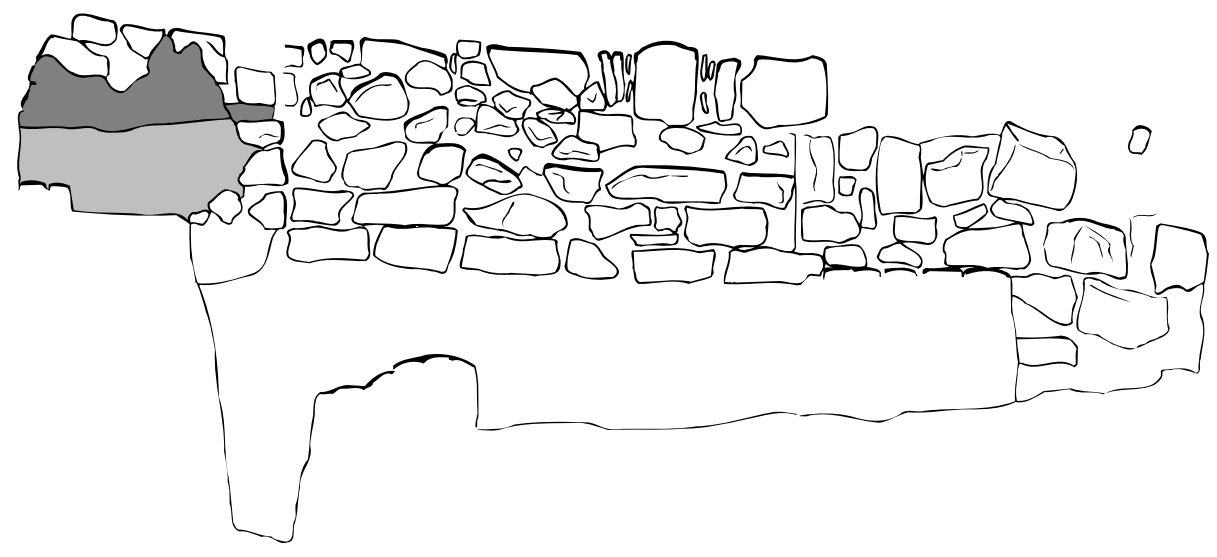

Yeso

Yeso con pintura roja

Fig. 6 

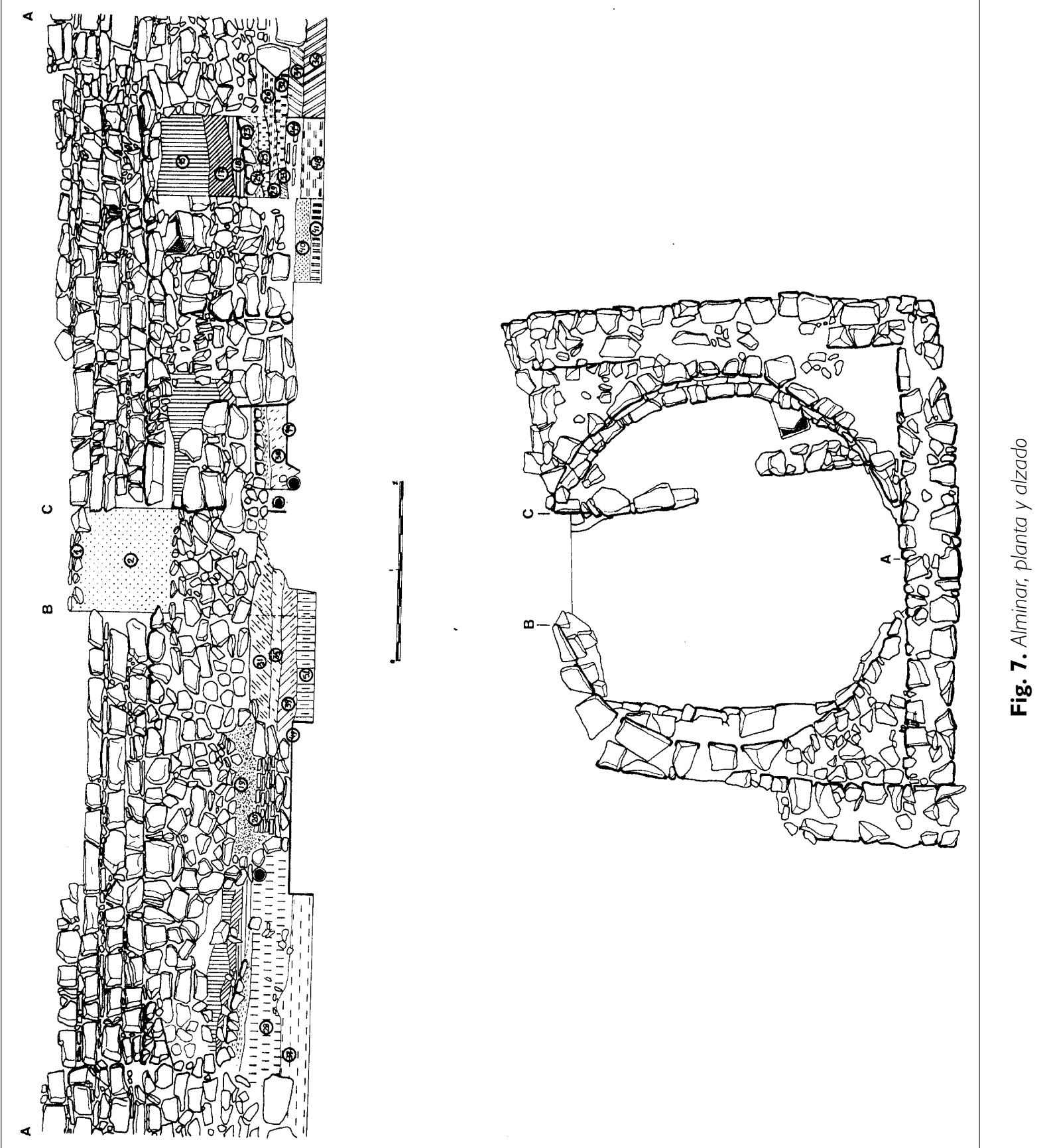


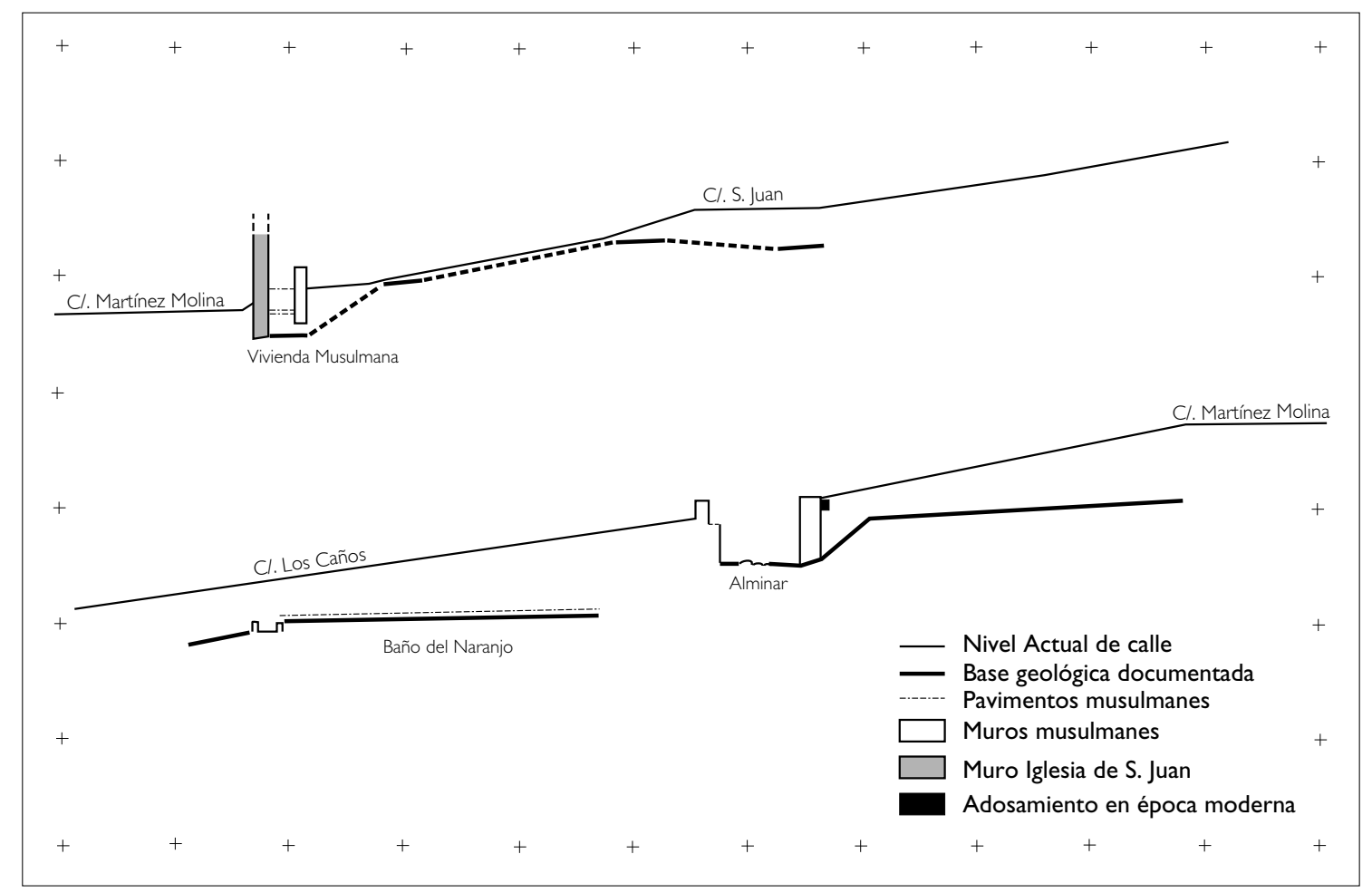

Fig. 8

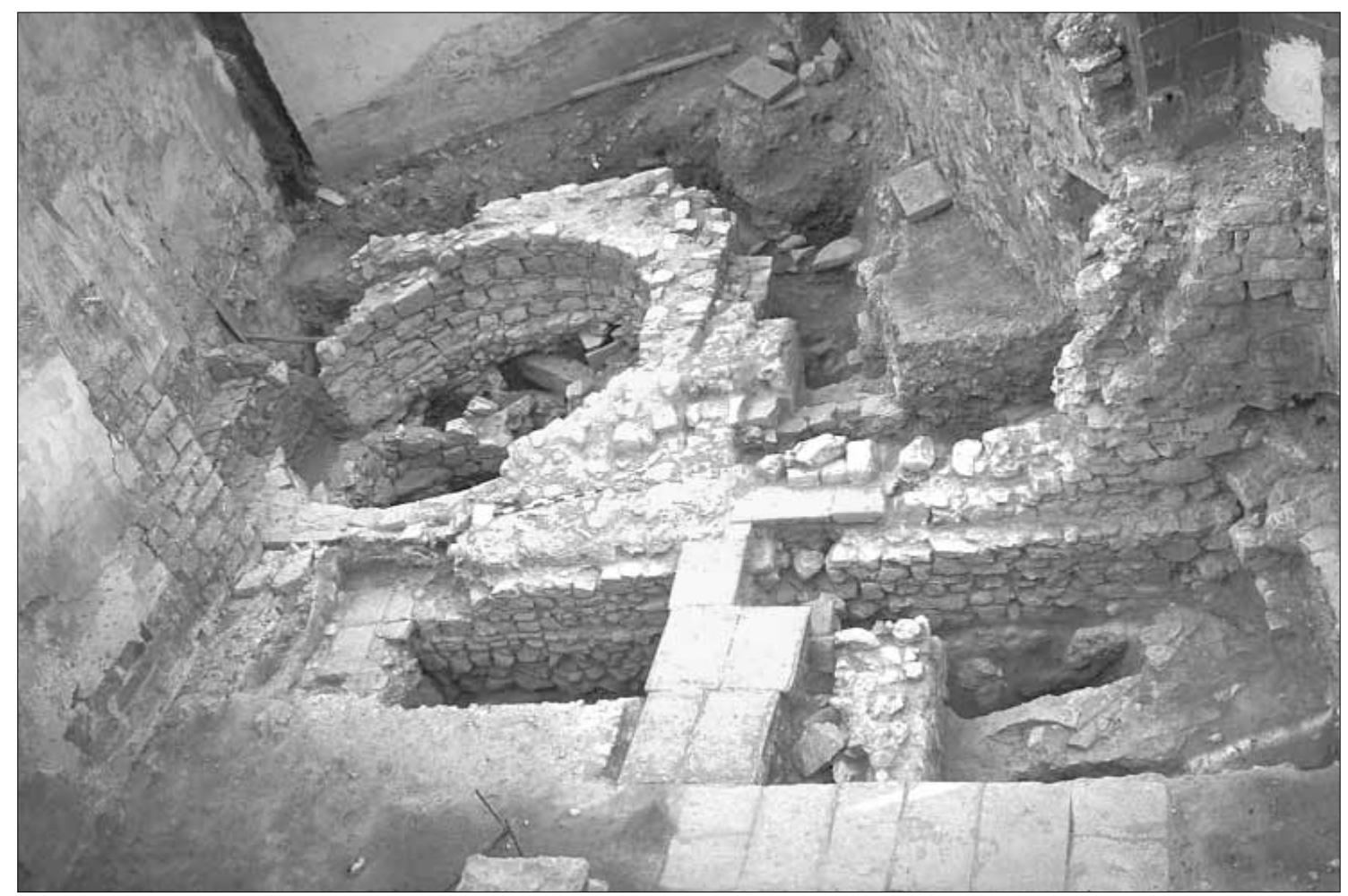

Lám. I 